\title{
Anthropometry of the Coracoid Process: Surgical Considerations in Arthroscopic Coracoclavicular Ligament Reconstruction
}

\section{Somsak Kuptniratsaikul}

Chulalongkorn University Faculty of Medicine

\section{Natavut Prasertkul}

Chulalongkorn University Faculty of Medicine

Thun Itthipanichpong ( $\square$ thunthedoc@gmail.com )

Department of Orthopaedics, Faculty of Medicine, King Chulalongkorn Memorial Hospital, Bangkok, Thailand https://orcid.org/0000-0002-8640-1651

\section{Research article}

Keywords: Arthroscopic coracoclavicular ligament reconstruction, coracoid fracture, safe area, drill bit size

Posted Date: August 20th, 2020

DOl: https://doi.org/10.21203/rs.3.rs-54608/v1

License: (c) (i) This work is licensed under a Creative Commons Attribution 4.0 International License. Read Full License 


\section{Abstract}

Purposed: The purpose of this study was to measure the dimensions of the coracoid process from MRI imaging to find a safe area for drilling in arthroscopic coracoclavicular ligament reconstruction.

Materials and methods: A retrospective study of patients who underwent MRI of the shoulder in our hospital between July 1, 2016 and June 31, 2018. Inclusion criteria included patients aged 20-60 years, $\mathrm{BMl}<35$ and height $>150 \mathrm{~cm}$. Exclusion criteria included patients with a history of coracoid surgery, coracoid fracture or bone diseases affecting the coracoid bone. Measurement of the coracoid size was done in T1 MRI sagittal, coronal and axial views. Safe zone was defined as an area far from the medial and lateral base of the coracoid process, at least $5 \mathrm{~mm}$ each. Safe zone was then compared with the size of the drill hole to find an appropriately sized drill that would not violate the peripheral cortical coracoid bone.

Results: Overall, 100 (male $=55$, female $=45$ ) patients were included in this study. Mean age, BMI and height of the patients were 48.5 years (range 22-58), $22.5 \mathrm{~kg} / \mathrm{m}^{2}$ (range 18.5-28.4) and $164.5 \mathrm{~cm}$ (range 155-182), respectively. Mean safe area was $167.45 \mathrm{~mm}^{2}$ with males being slightly larger than females (male $=190.34 \mathrm{~mm}^{2}$, female $\left.=140.99 \mathrm{~mm}^{2}\right)$. The drill hole area was calculated by the radius $(r)$ of the drill ( compared with the safe area. The maximum drill size for the men was $7 \mathrm{~mm}\left(154 \mathrm{~mm}^{2}\right.$ ) and $6 \mathrm{~mm}$ $\left(113.14 \mathrm{~mm}^{2}\right)$ for women. However, we recommended a smaller drill size to account for any errors in position and technique.

Conclusion: The safe area at the coracoid base was slightly larger in males as compared to females and the proper drill bit size was suggested to be less than $7 \mathrm{~mm}$ in males and $6 \mathrm{~mm}$ in females.

\section{Introduction}

Acromioclavicular (AC) joint (ACJ) separation is a common injury that can result from sports activities and direct impact to the lateral aspect of the shoulder.Reconstruction of the coracoclavicular ligament may improve biomechanical function and clinical outcome.(1)

Arthroscopic coracoclavicular ligament reconstruction with cortical suspension at the coracoid base has benefit in the treatment of ACJ injuries due to its better visualization, identification of occult intra-articular pathologies and less chance of soft tissue injuries when compare with open surgery. Nevertheless, complications such as persistent instability, loss of reduction, coracoid fracture, slip of the coracoid button with subsequent recurrent vertical instability and wound infection were observed.(2)One of the potential risks of this procedure is fracture of the coracoid process from the improper positioning and sizing of the drill hole(3), which leads to failure of treatment and the increased morbidity of the patient.

The purpose of this study was to measure the dimensions of the coracoid process from MRI to identify a safe area for drilling. We hypothesized that safe area for coracoid drilling was smaller in female compared to that in male. 


\section{Materials And Methods}

This study was retrospective descriptive study. One hundred patients (55 men and 45 women) who underwent MRI of the shoulder in hospital between July 1, 2016 and June 31, 2018 were enrolled.The inclusion criteriaincluded: (1) Patients aged 20-60 years, (2) BMl $<35 \mathrm{~kg} / \mathrm{m}^{2}$ and (3) height $>150 \mathrm{~cm}$. The exclusion criteriaincluded patients with a history of (1) coracoid surgery, (2) coracoid fracture and (3) bone diseases affecting the coracoid bone.

Measurements of the coracoid size were done in T1 MRI sagittal, coronal and axial views by one orthopedic resident and one radiologist. Tip width, base width and length were measured in a T1 MRI axial view (Fig. 1). Tip height and base height were measured in a T1 MRI sagittal view (Fig. 2). Insertion of the trapezoid and conoid ligaments was identified in T1 MRI axial and coronal views. Measurements were repeated three times with a 2 week interval.Intra-observer and inter-observer reliability were calculated withIntraclass Correlation Coefficients (ICC), 0.86 and 0.65 respectively.

Safe zone was defined as an area far from the medial and lateral coracoid border at least $5 \mathrm{~mm}$ each.(4) The upper border included the insertion of the trapezoid ligament, and the lower border included the coracoid base. We measured the safe area by formula area of the trapezoid (Fig. 3). The safe zone was then compared with the size of the drill hole to find an appropriately sized drill that would not violate the peripheral cortical coracoid bone.

Sample size was calculated based on measurements of the coracoid process from a previous study.(5) To achieve an alpha of 0.05 and beta of 0.20 with $80 \%$ power, it required 50 patients.

Statistical analyses included means with standard deviations and unpaired t-tests.Statistical analyses were performed with SPSS (Statistical Package of Social Sciences, Chicago, IL, USA). The level of statistical significance was set at a P-value $<0.05$.

\section{Results}

All demographic data are illustrated in Table 1. There were no significant differences noted between either of the groups except for height $(P<0.0001)$

The coracoid measurements are illustrated in Table 2. There were significant differences between both groups in terms of length $(P<0.0001)$, base width $(P<0.0001)$ and tip width $(P=0.02)$.

The safe area measurement is illustrated in Table 3. There were significant differences between both of the groups $(P<0.0001)$.

\section{Discussion}

Nowadays, many techniques for the restoration of coracoclavicular ligaments have been reported with improved biomechanical function and clinical outcomes.(6) In transclavicular-transcoracoidal tunnel 
procedures, accurate placement may reduce the risk of repair failure and cortical breach, as described in recent anatomic considerations for transclavicular-transcoracoid drilling for coracoclavicular ligaments. (3-5) It has been suggested that transclavicular-transcoracoid drilling should be approached with caution $^{5}$, because during the formation of a coracoid bone tunnel, central positioning and a proper trajectory of the drill could help reduce the risk of coracoid process fracture and repair failure.(3) This maybe the result of several factors, including the consideration of anatomical landmarks and variations(7-8), bone tunnel malposition(3) and avoiding multiple drilling of the coracoid that weakens the bone, among others.

Previous studies have reported on the anatomic measurements of the coracoid process and the footprint of the coracoclavicular ligaments.(7-10)Salzmann et al.(7) reported a length of approximately $4.31 \pm 0.22$ $\mathrm{cm}$ and a width and height at the tip of $1.36 \pm 0.21$ and $0.82 \pm 0.1 \mathrm{~cm}$, respectively. Rios et al. (8) reported a length of approximately $4.52 \pm 0.41 \mathrm{~cm}$ and a width and height at the base of $2.49 \pm 0.25$ and $1.19 \pm$ $0.18 \mathrm{~cm}$, respectively.Dolan et al.(9) reported a value for the distance from the tip to the trapezoid ligament of $2.85 \mathrm{~cm}$ and a mean coracoid length, tip width and tip height of $4.56,1.83$ and $1.15 \mathrm{~cm}$, respectively. Terra et al. (10) reported a mean for the distance from the tip to trapezoid ligament of 3.33 $\mathrm{cm}$ and a mean coracoid length, tip width and tip height of $4.26,1.49$ and $2.11 \mathrm{~cm}$, respectively.As expected, men had a significantly longer coracoid, greater coracoid tip width and height and a greater coracoid base width and height than women.(7-10) The coracoid processes in our study were smaller when compared to previous studies, which may be due to the ethnicity of the participants.(7-10)

The mean safe area was $167.45 \mathrm{~mm}^{2}$ with males being slightly larger than females (male $=190.34 \mathrm{~mm}^{2}$, female $=140.99 \mathrm{~mm}^{2}$ ). The drill hole area was calculated by the radius $(r)$ of the drill ( compared with the safe area. The maximum drill size for men was size $7 \mathrm{~mm}\left(154 \mathrm{~mm}^{2}\right)$ and $6 \mathrm{~mm}\left(113.14 \mathrm{~mm}^{2}\right)$ for women. However, we recommend a smaller drill size to account any errors in positioning and technique.

\section{Conclusion}

The safe area at the coracoid base was slightly larger in males as compared to females and a proper drill bit size is suggested to be less than $7 \mathrm{~mm}$ in males and $6 \mathrm{~mm}$ in females.

\section{Declarations}

\section{Compliance with Ethical Standards}

Conflict of Interest: The authors declare that they have no conflict of interest.

Funding: There is no funding source.

Ethical approval:The study was approved by Institutional Review Board Faculty of Medicine Chulalongkorn University, IRB No.307/62

\section{References}


${ }^{1}$ Walz L, Salzmann GM, Fabbro T, Eichhorn S, Imhoff AB (2008) The anatomic reconstruction of acromioclavicular joint dislocations using 2 TightRope devices: a biomechanical study. Am J Sports Med 36(12):2398-2406

2 Woodmass JM,Esposito JG,Ono Y,Nelson AA,Boorman RS,Thornton GM,Lo IK (2015) Complications following arthroscopic fixation of acromioclavicular separations: a systematic review of the literature. Open Access J Sports Med. 6:97-107

${ }^{3}$ Ferreira JV, Chowaniec D, Obopilwe E, Nowak MD, Arciero RA, Mazzocca AD (2012) Biomechanical evaluation of effect of coracoid tunnel placement on load to failure of fixation during repair of acromioclavicular joint dislocations. Arthrosc J Arthrosc Rel Surg Off Pub Arthrosc Assoc North Am Int Arthrosc Assoc 28(9):1230-1236

${ }^{4}$ Theopold J,Weihs K,Löffler S,Marquass B,von Dercks N,Josten C,Hepp P. (2015) Image-free navigated coracoclavicular drilling for the repair of acromioclavicular joint dislocation: a cadaver study. Arch Orthop Trauma Surg 135:1077-1082

${ }^{5}$ Coale RM, Hollister SJ, Dines JS, Allen AA, Bedi A (2013) Anatomic considerations of transclaviculartranscoracoid drilling for coracoclavicular ligament reconstruction. J Shoulder Elbow Surg Am Shoulder Elbow Surg 22(1):137-144.

${ }^{6}$ Thomas K, Litsky A, Jones G, Bishop JY. (2011) Biomechanical comparison of coracoclavicular reconstructive techniques. Am J Sports Med 39:804-10

${ }^{7}$ Salzmann GM, Paul J, Sandmann GH, Imhoff AB, Schottle PB(2008) The coracoidal insertion of the coracoclavicular ligaments: an anatomic study. Am J Sports Med 36(12):2392-2397

${ }^{8}$ Rios CG, Arciero RA, Mazzocca AD (2007) Anatomy of the clavicle and coracoid process for reconstruction of the coracoclavicular ligaments. Am J Sports Med 35(5):811-817

${ }^{9}$ Dolan CM, Hariri S, Hart ND, McAdams TR.(2011) An anatomic study of the coracoid process as it relates to bone transfer procedures. J Shoulder Elbow Surg 20:497-501

${ }^{10}$ Terra BB,Ejnisman B,de Figueiredo EA,Cohen C,Monteiro GC,de Castro Pochini A,Andreoli CV,Cohen M. (2013) Anatomic Study of the Coracoid Process: Safety Margin and Practical Implications. Arthroscopy. 29(1):25-30

\section{Tables}

Table 1. Demographic data 


\begin{tabular}{|ccccccc|}
\hline Parameter & \multicolumn{5}{c|}{ Study Group } \\
& $\begin{array}{c}\text { Total } \\
(\mathbf{N}=100)\end{array}$ & $\begin{array}{c}\text { Male } \\
(\mathbf{N}=\mathbf{5 5})\end{array}$ & $\begin{array}{c}\text { Female } \\
\mathbf{( N = 4 5 )}\end{array}$ & Mean Difference & 95\% Confidence Interval & P-value \\
\hline Age(year) & 48.5 & 48.2 & 48.8 & 0.6 & $-0.99,2.19$ & 0.45 \\
\hline BMI(kg/m $\left.\mathbf{m}^{2}\right)$ & 22.5 & 21.9 & 23.2 & 1.3 & $-0.29,2.89$ & 0.10 \\
Height(cm) & 164.5 & 170.2 & 157.5 & 12.7 & $11.10,14.29$ & $<0.0001$ \\
\hline
\end{tabular}

Data were analyzed with an independent t-test $(\mathrm{P}<0.05$ : Significant difference)

Table 2. Coracoid measurements

\begin{tabular}{|c|c|c|c|c|c|c|}
\hline \multirow[t]{2}{*}{ Variable } & \multicolumn{6}{|c|}{ Coracoid Measurements } \\
\hline & $\begin{array}{c}\text { Total } \\
(\mathrm{N}=100)\end{array}$ & $\begin{array}{c}\text { Male } \\
(\mathrm{N}=55)\end{array}$ & $\begin{array}{l}\text { Female } \\
(\mathrm{N}=45)\end{array}$ & $\begin{array}{c}\text { Mean } \\
\text { Difference }\end{array}$ & $\begin{array}{l}\text { 95\% Confidence } \\
\text { Interval }\end{array}$ & P-value \\
\hline Length(mm) & 38.86 & 40.8 & 36.5 & 4.3 & $2.91,5.69$ & $<0.0001$ \\
\hline $\begin{array}{c}\text { Base } \\
\text { width }(\mathrm{mm})\end{array}$ & 32.56 & 34.5 & 30.2 & 4.3 & $2.70,5.89$ & $<0.0001$ \\
\hline $\begin{array}{c}\text { Base } \\
\text { height(mm) }\end{array}$ & 10.91 & 11.5 & 10.2 & 1.3 & $-0.29,2.89$ & 0.10 \\
\hline Tip width(mm) & 10.69 & 11.55 & 9.65 & 1.9 & $0.30,3.49$ & 0.02 \\
\hline Tip height(mm) & 7.85 & 8.2 & 7.42 & 0.78 & $-0.81,2.37$ & 0.33 \\
\hline
\end{tabular}

Data were analyzed with an independent t-test $(\mathrm{P}<0.05$ : Significant difference)

Table 3. Safe area measurements 


\begin{tabular}{|c|c|c|c|c|c|c|}
\hline \multirow[t]{2}{*}{ Variable } & \multicolumn{6}{|c|}{ Safe Area Measurements } \\
\hline & $\begin{array}{c}\text { Total } \\
(\mathrm{N}=100)\end{array}$ & $\begin{array}{c}\text { Male } \\
(\mathrm{N}=55)\end{array}$ & $\begin{array}{l}\text { Female } \\
(\mathrm{N}=45)\end{array}$ & $\begin{array}{c}\text { Mean } \\
\text { Difference }\end{array}$ & $\begin{array}{l}\text { 95\% Confidence } \\
\text { Interval }\end{array}$ & P-value \\
\hline $\mathrm{A}(\mathrm{mm})$ & 5.49 & 6.45 & 4.32 & 2.13 & $0.53,3.72$ & 0.0094 \\
\hline $\mathrm{B}(\mathrm{mm})$ & 22.56 & 24.5 & 20.2 & 4.3 & $2.70,5.89$ & $<0.0001$ \\
\hline $\mathrm{H}(\mathrm{mm})$ & 11.94 & 12.3 & 11.5 & 0.8 & $-0.39,1.99$ & 0.18 \\
\hline $\begin{array}{c}\text { Area } \\
\text { Safe }\left(\mathrm{mm}^{2}\right)\end{array}$ & 167.45 & 190.34 & 140.99 & 49.35 & $47.75,50.94$ & $<0.0001$ \\
\hline
\end{tabular}

Data were analyzed with an independent t-test $(\mathrm{P}<0.05$ : Significant difference)

Figures 


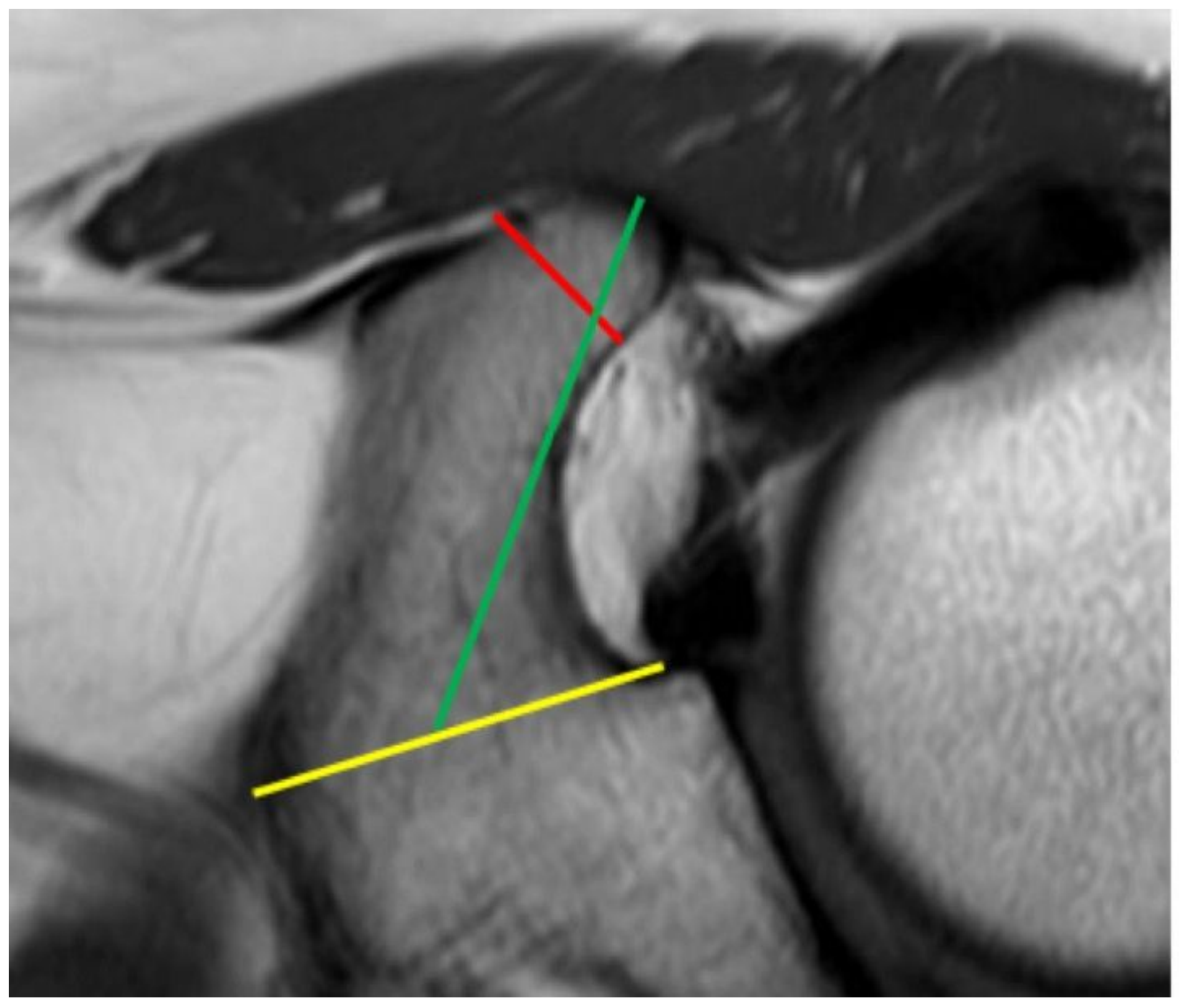

Figure 1

T1 MRI in an axial view showing the tip width in red, base width in yellow and length in green. 


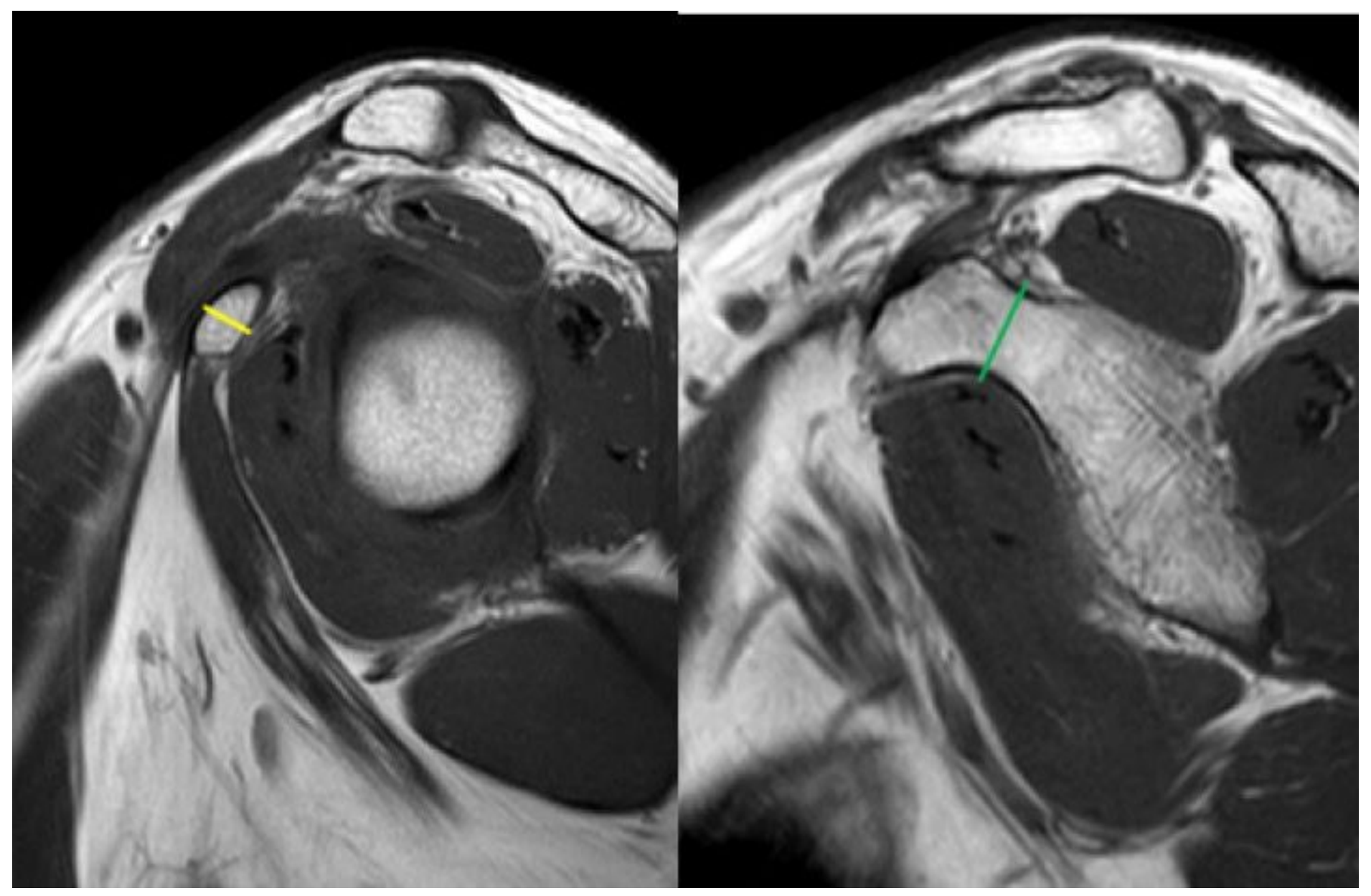

\section{Figure 2}

T1 MRI in a sagittal view showing tip height in yellow and base height in green. 

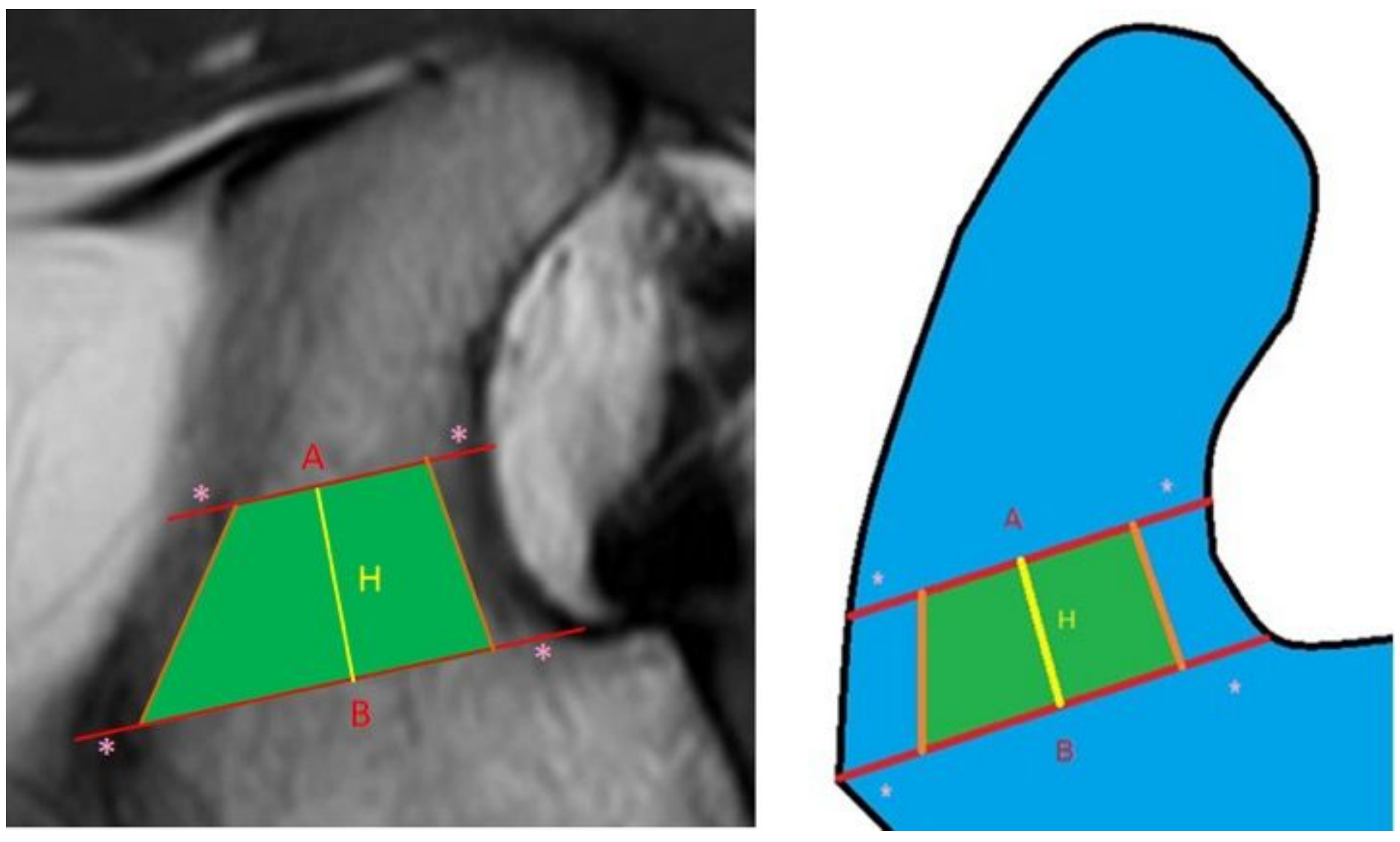

\section{Figure 3}

The green area was the safe area generated from the formula area of the trapezoid $1 / 2(A+B)(H), A$ : Insertion of the trapezoid ligament, B: Coracoid base, $\mathrm{H}$ : Distance between the trapezoid ligament insertion and coracoid base and *: "Error in tunnel placement" defined as $5 \mathrm{~mm}$ from the medial and lateral coracoid border. 